\title{
Analysis of a New Index for the Thermal Performance of Horizontal Opaque Building Components in Summer
}

\author{
Hashem Akbari ${ }^{1}$, Chiara Lodi ${ }^{2}$, Alberto Muscio ${ }^{2, *(D)}$ and Paolo Tartarini ${ }^{2}$ \\ 1 Gina Cody School of Engineering and Computer Science, Concordia University, \\ Montreal, QC H3G 1M8, Canada; hakbari@encs.concordia.ca \\ 2 Department of Engineering “Enzo Ferrari”, University of Modena \& Reggio Emilia, 41124 Modena, Italy; \\ chiaralodi4@gmail.com (C.L.); paolo.tartarini@unimore.it (P.T.) \\ * Correspondence: alberto.muscio@unimore.it
}

Citation: Akbari, H.; Lodi, C.;

Muscio, A.; Tartarini, P. Analysis of a New Index for the Thermal Performance of Horizontal Opaque Building Components in Summer. Atmosphere 2021, 12, 862. https:// doi.org/10.3390/atmos12070862

Academic Editors:

Hideki Takebayashi and Jihui Yuan

Received: 18 June 2021

Accepted: 29 June 2021

Published: 2 July 2021

Publisher's Note: MDPI stays neutral with regard to jurisdictional claims in published maps and institutional affiliations.

Copyright: (c) 2021 by the authors. Licensee MDPI, Basel, Switzerland. This article is an open access article distributed under the terms and conditions of the Creative Commons Attribution (CC BY) license (https:// creativecommons.org/licenses/by/ $4.0 /)$.

\begin{abstract}
The summer behavior of an opaque building component subjected to the solar cycle depends on the combination of its thermal insulation, inertia, and solar reflectance. To rate the component dynamic behavior while an air conditioning system ensures a steady indoor temperature, a 'solar transmittance index' (STI) has been proposed. This is a component-based index calculated from a 'solar transmittance factor' (STF). STI takes into account the radiative properties at the outer surface and the thermophysical properties and layer structure of the materials beneath. It correlates the peak heat flux and temperature at the inner surface, relevant to cooling energy and thermal comfort, to the peak solar irradiance. Similar to the well-known 'solar reflectance index', STI is determined comparing the STF with two reference values, corresponding to a performance relatively low and very high, respectively. Thanks to its simplicity, the approach may allow defining easy to apply requirements to prevent building overheating, improve indoor comfort, reduce cooling energy demand, and mitigate some fallouts of the urban heat island effect. In this work, focused on roofs above occupied attics, peak heat flux and ceiling temperature are calculated by numerical simulation and compared with STF values for a wide range of roof types.
\end{abstract}

Keywords: building cooling; periodic thermal transmittance; roof; solar reflectance; SRI; thermal inertia; thermal insulation; thermal transmittance

\section{Introduction}

An approach to calculate the performance of a building relies upon dynamic simulation models, applied on an hourly basis or shorter and taking into account a wide set of parameters. Main relevant parameters are the climate at the installation site, with the relevant meteorological variables and their seasonal and daily cycles, and the dynamic performance of the building envelope. The dynamic performance is influenced by the insulation and the inertia of the building components and their surface properties relevant to solar gains, as well as the characteristics of the transparent components and their shading or sunscreen. Other aspects to be considered are the response of the different components of the heating, cooling, and air conditioning (HVAC) system as controlled by building automation devices and the complex interaction between climate, envelope, HVAC systems, and usage profile. This can provide an objective prediction of the energy needs for HVAC, both in reference conditions and in actual or extrapolated scenarios. Such prediction can be used to assign a class of energy performance to the building, or to evaluate the cost-effectiveness of energy retrofit actions.

An opposite approach is that of calculating the building energy needs with a simplified procedure, e.g., based on an almost stationary heat balance evaluated on a daily or a monthly basis, neglecting the fluctuation of the meteorological parameters and the dynamic interaction of the envelope with the HVAC system. This may, however, lead to 
a significant discrepancy between the calculated and actual building performance. Therefore, to limit the risk that a required performance target is not really achieved, additional and highly demanding requirements are often imposed for single components of the building envelope and the HVAC system. This is the line of the regulatory system in force in Italy since 2007, where the class of performance is generally based on the results of the simplified calculation method described in the UNI/TS 11300 set of technical rules, i.e., the national implementation of ISO 13790 [1], for building heating and cooling [2]. For new or renovated buildings, stringent minimum requirements have been imposed for the U-value and the periodic thermal transmittance of opaque components, the U-value and the solar factor of transparent components, the solar reflectance of roof surfaces, etc. [3]; even more stringent requirements must be fulfilled to obtain economic incentives for building retrofitting [4]. According to current rules, the calculation of the thermal behavior and the energy performance of the whole building may even be unnecessary in case a partial retrofit is implemented, provided that the minimum requirements are satisfied for the retrofitted components of the envelope and/or the HVAC system.

Of course, intermediate lines are possible between the above two outlined approaches.

The detailed and accurate dynamic calculation of the building thermal behavior, in realistic climatic and usage conditions, requires a substantial effort from the designers, often not supported by adequate preparation and design tools, or not economically justified by the extent of the energy retrofit action. If it is, however, made compulsory by regulation, the probability of a superficial and unreliable implementation is high. On the other hand, a large part of the construction professionals possess preparations and tools to calculate and verify the performance requirements on single building components, which can also be verified with relative ease by supervisory bodies. Moreover, focusing on the requirements at the component level can be effective for the winter heating of buildings with ordinary characteristics, while indoor and outdoor temperatures do not vary significantly along the day, and a proper closed-loop control of the heating system can balance the variability of the relatively weak solar gains. Instead, some concern is justified for summer heating, when fluctuating heat loads induced by the solar cycle become dominant, and therefore, one cannot ignore their dynamic interaction with the building envelope. Setting separate and independent requirements for thermal insulation and thermal inertia, however, may lead to an over-insulated envelope that prevents dissipation of solar gains, to uselessly massive walls and roof that increase cost and seismic risk, or to the use of less durable materials. Furthermore, in the presence of a building component such as a cool roof, characterized by a high solar reflectance at the outer surface, fulfilling additional and separate requirements for both thermal insulation and inertia may not provide additional benefits in terms of the overall thermal response of the component in summer.

Component-based requirements can help obtain a decent behavior of the building in the cold season, when heating is dominant. In fact, in this period, most of the requirements can be inherent to the thermal insulation of opaque and transparent building components, as well as to the prevention of moisture condensation by means of indoor ventilation and the correction of thermal bridges. In this regard, requirements on opaque components can be simply set in terms of minimum limits to the R-value $\left(\mathrm{m}^{2} \cdot \mathrm{K} \cdot{ }^{-1}\right)$, or maximum limits to its inverse, the U-value or thermal transmittance $\left(\mathrm{W} \cdot \mathrm{m}^{-2} \cdot \mathrm{K}^{-1}\right)$, calculated according to standard methods such as ISO 6946 [5]. In the hot season, however, the thermal behavior of an opaque building component depends also on its mass and heat capacity. More specifically, the dynamic response of the component is affected by parameters such as modulus of the periodic thermal transmittance, thermal admittance, decrement factor, or time shift, all of them defined in standard methods such as ISO 13786 [6]. Moreover, the reflectance of solar radiation directly at the external surface can be more effective than both thermal insulation and inertia in many cases. Hence, the requirements and/or incentives have been set for solar reflectance, a surface property usually measured according to ASTM C1549 [7] or ASTM E903 [8]. 
Another surface property, thermal emittance, usually measured according to EN 15976 [9] or ASTM C1371 [10], is seldom considered even if it affects the calculation of solar gains. Indeed, in ordinary buildings with a minimum level of thermal insulation, imposed to limit heat loss in winter, a proper dynamic performance of the opaque components, combined with indoor ventilation and an adequate sizing and shading of transparent components, can reasonably provide a decent summer performance in mild climates. This would limit the energy needed by the air conditioning system to achieve a comfortable indoor condition. More generally, the synergic fulfilling of a few properly identified performance requirements at the component level may lead to a satisfactory overall performance in both winter and summer. This would allow for promoting a faster and generalized enhancement of building lots. For the summer performance of opaque building components, however, requirements at the component level involve parameters that are weakly related or unrelated. It has already been underlined that they may result as largely superfluous-if not penalizing - in terms of cost, mass load, seismic risk, durability, fire risk, etc. On the other hand, the combined effect of both mass and surface properties on the indoor temperature at the building level can be accurately estimated only by numerical [11-14] or experimental techniques [15]. However, these relatively complex assessment approaches can seldom be used for an expeditious selection of the optimal building solution as they are out of reach for many designers and construction firms. In the end, a single performance parameter that reflects the dynamic response of an opaque building component, for which simple requirements can be set, would be highly desirable.

An interesting approach to classify roof and wall components that takes into account both surface and mass properties is that of the 'thermal performance index' (TPI). In this index, a rating value of 100 (the lower the better) is assigned for a given excess of peak temperature at the ceiling of an unconditioned space or for a given peak of heat flow rate per unit of ceiling surface of a conditioned space [16]. A modification of the approach was recently proposed [17] with the 'new' thermal performance index ( $\left.{ }^{*} \mathrm{TPI}\right)$, in which the rating value of 100 (the higher the better) is assigned for the decrease of ceiling temperature of an optimal roof solution with respect to the ceiling temperature achieved in the worst case of a galvanized iron roof. Another component-based indicator is proposed in [18], where the R-factor and outer solar reflectance of a roof are combined in an equivalent thermal resistance, increased with respect to the actual one thanks to an enhanced solar reflectance. The need of taking into account not only solar reflectance but also heat capacity is shown in [19]. A comprehensive model of the roof thermal behavior, focused on the double skin roof type, is reported in [20].

With increasing complexity, a set of Environmental Resource Indicators (ERI) is proposed in [21] as building performance indicators, representing the exploitable environmental resources (external air through external convection, natural ventilation, and sky radiation cooling), but their calculation is not immediate. In ref. [22], a methodology and some indexes are proposed to evaluate the building indoor environment and its anthropogenic heat transferred to the environment, yet again based on a simulation approach. Generally speaking, the requirements to prevent building overheating are difficult to identify and verify, be they are conceived as a mere set of limits at the component level or in terms of synthetic comfort indicators such as the 'hot thermal performance index' (TPIh) and the 'hot discomfort degree hour' index (DDHh) analyzed in [13], or the 'thermal deviation index' (TDI) proposed in [23].

In a previous work [24], a 'solar transmittance index' (STI) was proposed to rate the overall dynamic thermal behavior of an opaque building component when its external surface is subjected to the cycle of solar radiation and the indoor temperature is kept constant. STI includes, in a single performance parameter, both the radiative properties at the external surface and the thermophysical properties of the materials under the surface. It is developed by a procedure similar to that of *TPI [17] but with an approach independent of the installation site and aimed to obtain the maximum ease of calculation. More specifically, the solar transmittance index (STI) is based on a multiplicative factor, 
the solar transmittance factor (STF). This correlates the peak heat flux at the inner surface, relevant to the energy need for air conditioning, to the peak solar irradiance. The radiative properties at the outer surface and the thermophysical properties and layer structure of the materials beneath are taken into account. The peak heat flux is in turn correlated to the inner surface temperature, relevant to thermal comfort. Similar to the well-known 'solar reflectance index' (SRI), as defined in ASTM E1980 [25,26], it has been proposed that STI is determined comparing the abovementioned correlation factor STF with two reference values, corresponding to a performance relatively low and very high, respectively, in order to clearly differentiate the performance of different solutions. With their simplicity, STF and STI may allow defining easy to apply requirements to prevent building overheating, improve indoor thermal comfort, reduce cooling energy demand, and mitigate some fallouts of the urban heat island effect.

In this work, focused on roofs above inhabited attics for which thermal insulation is prescribed, the heat flux and peak temperature are calculated by numerical simulation at the ceiling surface and are compared with the STF values. The comparison is made for a relatively wide range of roof types and layer structures in different environmental conditions in order to verify the existence of a significant correlation. The focus is on the roof as it is the main source of heat gains in the interior heat balance, often higher than the direct solar gains through windows [27].

\section{Materials and Methods}

\subsection{Mass and Surface Performance Parameters}

The development of the solar transmittance index is detailed in [24]. The main concepts are summarized below for sake of completeness.

The thermal insulation provided by a building component can be evaluated in terms of U-value $\left(\mathrm{W} \cdot \mathrm{m}^{-2} \cdot \mathrm{K}^{-1}\right)$, defined for steady-state conditions as the ratio of the heat flux density $\mathrm{q}\left(\mathrm{W} \cdot \mathrm{m}^{-2}\right)$ to the temperature difference across the component, i.e., between the external temperature $T_{e}$ and the internal temperature $T_{i}$ with a positive entering heat flux, as follows:

$$
\mathrm{U} \equiv \frac{1}{\mathrm{R}}=\frac{\mathrm{q}}{\mathrm{T}_{\mathrm{e}}-\mathrm{T}_{\mathrm{i}}}
$$

The inverse of the U-value, the R-value, or the thermal resistance $\left(\mathrm{m}^{2} \cdot \mathrm{K} \cdot \mathrm{W}^{-1}\right)$ of the whole component is also defined. Both $\mathrm{U}$ and $\mathrm{R}$ are calculated according to ISO [5], ASHRAE [28], or other equivalent standards from the sum of the conductive resistances of the component layers with their thickness $\mathrm{L}(\mathrm{m})$ and thermal conductivity $\mathrm{k}\left(\mathrm{W} \cdot \mathrm{m}^{-1} \cdot \mathrm{K}^{-1}\right)$, and the heat transfer coefficients, $h_{e}$ and $h_{i}\left(W \cdot m^{-2} \cdot K^{-1}\right)$, at the external and internal surfaces:

$$
\mathrm{U} \equiv \frac{1}{\mathrm{R}}=\frac{1}{\frac{1}{\mathrm{~h}_{\mathrm{e}}}+\sum \frac{\mathrm{L}}{\mathrm{k}}+\frac{1}{\mathrm{~h}_{\mathrm{i}}}}
$$

Either $h_{e}$ or $h_{i}$ are given by the combination of a convection coefficient, $h_{c e}$ or $h_{c i}$, and a radiation coefficient, $h_{\text {re }}$ or $h_{\mathrm{ri}}$ :

$$
\begin{aligned}
& h_{e}=h_{c e}+h_{r e}=h_{c e}+\varepsilon_{e} \cdot\left(\frac{T_{\text {sky }}^{4}-T_{s e}^{4}}{T_{\text {sky }}^{4}-T_{\text {se }}}\right) \\
& h_{i}=h_{c i}+h_{r i}=h_{c i}+\varepsilon_{i} \cdot \sigma_{0} \cdot\left(\frac{T_{s i}^{4}-T_{i}^{4}}{T_{s i}-T_{i}}\right)
\end{aligned}
$$

where $T_{\text {sky }}, T_{\text {se, }}$, and $T_{\text {si }}(K)$ are the sky temperature and the external and internal surface temperatures, respectively. The internal convection coefficient $h_{\mathrm{ci}}$ is generally induced by the free convection phenomena and it can be an almost-constant value, changing only with the direction of the heat flux. The external convection coefficient $h_{c e}$ also depends on wind velocity. Empirical values or formulas are available for their estimate, e.g., those in $[5,28]$. 
The radiation heat transfer coefficients are correlated to a maximum value that depends on $\mathrm{T}_{\mathrm{se}}$ and $\mathrm{T}_{\mathrm{si}}(\mathrm{K})$ through the Stefan-Boltzmann constant $\sigma_{0}=5.67 \times 10^{-8} \mathrm{~W} \cdot \mathrm{m}^{-2} \cdot \mathrm{K}^{-4}$ and the thermal emittance of the external and internal surfaces, $\varepsilon_{\mathrm{e}}$ and $\varepsilon_{\mathrm{i}}$.

The external temperature $T_{e}$ in Equation (1) is the weighted average of the air temperature $\mathrm{T}_{\text {air }}$ and the 'effective' sky temperature $\mathrm{T}_{\text {sky }}$ (which is in turn evaluated from the near-ground air temperature, the partial pressure of water vapor, and the view-factor between the considered surface and the sky by empirical formulas):

$$
\mathrm{T}_{\mathrm{e}}=\frac{\mathrm{h}_{\mathrm{ce}} \cdot \mathrm{T}_{\mathrm{air}}+\mathrm{h}_{\mathrm{re}} \cdot \mathrm{T}_{\mathrm{sky}}}{\mathrm{h}_{\mathrm{ce}}+\mathrm{h}_{\mathrm{re}}}
$$

When the outer surface of the considered building component is subjected to a solar irradiance $\mathrm{I}_{\mathrm{sol}}\left(\mathrm{W} \cdot \mathrm{m}^{-2}\right), \mathrm{T}_{\mathrm{e}}$ must be increased by the non-reflected fraction of the irradiance, divided by $h_{\mathrm{e}}$. The so-called sol-air temperature is obtained, whose definition includes the solar reflectance $\rho_{\text {sol }}\left(0<\rho_{\text {sol }}<1\right)$, i.e., the ratio of reflected and incident solar radiation:

$$
\mathrm{T}_{\text {sol-air }}=\mathrm{T}_{\mathrm{e}}+\frac{\left(1-\rho_{\text {sol }}\right)}{\mathrm{h}_{\mathrm{e}}} \cdot \mathrm{I}_{\mathrm{sol}}
$$

The combined effects of solar reflectance and external thermal emittance can also be expressed through the 'solar reflectance index' (SRI), a parameter calculated as specified in [25]:

$$
\mathrm{SRI}=100 \cdot \frac{\mathrm{T}_{\mathrm{sb}}-\mathrm{T}_{\mathrm{se}}}{\mathrm{T}_{\mathrm{sb}}-\mathrm{T}_{\mathrm{sw}}}
$$

In this case, $\mathrm{T}_{\text {se }}(\mathrm{K})$ is the temperature that the analyzed surface would steadily reach when irradiated by a reference solar flux $\mathrm{I}_{\mathrm{sol} \text {,max }}=1000 \mathrm{~W} \cdot \mathrm{m}^{-2}$ at atmospheric air temperature $\mathrm{T}_{\text {air }}=310 \mathrm{~K}$, sky temperature $\mathrm{T}_{\text {sky }}=300 \mathrm{~K}$, and with convection heat transfer coefficient $\mathrm{h}_{\mathrm{ce}}$ for which the values 5,12 , and $30 \mathrm{~W} \cdot \mathrm{m}^{-2} \cdot \mathrm{K}^{-1}$ are specified for low $\left(\mathrm{v}_{\text {wind }}<2 \mathrm{~m} \cdot \mathrm{s}^{-1}\right)$, intermediate $\left(2 \mathrm{~m} \cdot \mathrm{s}^{-1}<\mathrm{v}_{\text {wind }}<6 \mathrm{~m} \cdot \mathrm{s}^{-1}\right)$, and high $\left(6 \mathrm{~m} \cdot \mathrm{s}^{-1}<\mathrm{v}_{\text {wind }}<10 \mathrm{~m} \cdot \mathrm{s}^{-1}\right)$ wind speeds, respectively. $\mathrm{T}_{\mathrm{sb}}(\mathrm{K})$ and $\mathrm{T}_{\mathrm{sw}}(\mathrm{K})$ are the temperatures that would be reached by two reference surfaces, a black one $\left(\rho_{\mathrm{sol}, \mathrm{b}}=0.05\right)$ and a white one $\left(\rho_{\mathrm{sol}, \mathrm{w}}=0.80\right)$, respectively, both having high thermal emittance $\left(\varepsilon_{\mathrm{e}}=0.90\right)$. SRI represents the decrement of surface temperature that, in the reference conditions, the analyzed surface would allow with respect to the reference black one, divided by the decrement allowed by the reference white surface and given in percentage terms. The surface temperature $T_{\text {se }}$ (as well as $T_{s b}$ and $\mathrm{T}_{\mathrm{sw}}$ ) is determined by iteratively solving the following surface energy balance:

$$
\left(1-\rho_{\mathrm{sol}}\right) \cdot \mathrm{I}_{\mathrm{sol}}=\mathrm{h}_{\mathrm{ce}} \cdot\left(\mathrm{T}_{\mathrm{se}}-\mathrm{T}_{\mathrm{air}}\right)+\varepsilon_{\mathrm{e}} \cdot \sigma_{0} \cdot\left(\mathrm{T}_{\mathrm{se}}^{4}-\mathrm{T}_{\mathrm{sky}}^{4}\right)
$$

SRI is considered by voluntary rating systems such as LEED [29] when dealing with the summer performance of opaque building components, so it matches the need of a single performance parameter for different radiative surface properties and allows comparing the performance of different solar reflective or 'cool' solutions for roofs, walls, and pavements. Its main limitation is that it is based on the hypothesis of adiabatic external surface, and it is not affected by either the insulation or the inertia of the materials beneath. On the other end, the SRI works well even with non-adiabatic surfaces since the heat flux conducted inside can be lower by one or two orders of magnitude than the incident solar irradiance.

$\mathrm{T}_{\text {sol-air }}$ has a periodic time-evolution pattern that follows that of $\mathrm{I}_{\text {sol }}$. Their cycles peak at solar noon on a horizontal or almost horizontal surface and they are nil in the night. The external temperatures of the air and the sky may have a periodic time evolution pattern as well, following the cycle of solar irradiance with a short delay. When a strong cycle of the sol-air temperature occurs, the thermal problem becomes unsteady, and the thermal inertia of the envelope components gains significance. In this case, direct solutions to the heat transfer equation are generally unavailable and numerical methods would be needed, but the relatively simple approach to dynamic analysis provided by ISO 13786 [6] 
is also available and is widely used. It is based on that any periodic function such as the time evolution pattern of the sol-air temperature or solar irradiance can be decomposed into a Fourier series made of the sum of a (possibly infinite) set of simple oscillating functions, namely sines or cosines (or, equivalently, complex exponentials), with base period $\mathrm{t}_{0}=24 \mathrm{~h} \equiv 86^{\prime} 400 \mathrm{~s}$ :

$$
\begin{aligned}
& \mathrm{T}_{\text {sol-air }}(\mathrm{t})=\bar{\theta}_{\text {sol-air }}+\frac{\left(1-\rho_{\text {sol }}\right)}{h_{\mathrm{e}}} \cdot \sum_{\mathrm{n}=1}^{\infty}\left|\widehat{\theta}_{\text {sol-air, } \mathrm{n}}\right| \cdot\left(\mathrm{n} \cdot 2 \pi \cdot \frac{\mathrm{t}}{\mathrm{t}_{0}}+\psi_{\mathrm{n}}\right) \cong \\
& \cong \overline{\mathrm{T}}_{\mathrm{e}}+\frac{\left(1-\rho_{\text {sol }}\right)}{\mathrm{h}_{\mathrm{e}}} \cdot \overline{\mathrm{I}}_{\text {sol }}+\frac{\left(1-\rho_{\text {sol }}\right)}{\mathrm{h}_{\mathrm{e}}} \cdot \sum_{\mathrm{n}=1}^{\infty}\left|\widehat{\mathrm{I}}_{\text {sol, } \mathrm{n}}\right| \cdot\left(\mathrm{n} \cdot 2 \pi \cdot \frac{\mathrm{t}}{\mathrm{t}_{0}}+\psi_{\mathrm{n}}\right)
\end{aligned}
$$

where $\bar{\theta}_{\text {sol-air }}\left({ }^{\circ} \mathrm{C}\right)$ is the daily average value of the sol-air temperature and it depends on the daily average values of external temperature $\overline{\mathrm{T}}_{\mathrm{e}}\left({ }^{\circ} \mathrm{C}\right)$ and solar irradiance $\overline{\mathrm{I}}_{\text {sol }}\left(\mathrm{W} \cdot \mathrm{m}^{-2}\right)$. The nth harmonic of the sol-air temperature has an oscillation amplitude $\left|\widehat{\theta}_{\text {sol-air,n }}\right|\left({ }^{\circ} \mathrm{C}\right)$ depending on the amplitude of the $\mathrm{n}^{\text {th }}$ harmonic of the solar irradiance $\left|\widehat{\mathrm{I}}_{\mathrm{sol}, \mathrm{n}}\right|\left(\mathrm{W} \cdot \mathrm{m}^{-2}\right)$, and phase $\psi_{n}(\mathrm{rad})$. An approximation of Equation (8) consists of neglecting the cycle of the air temperature as its oscillation amplitude is relatively weak over urban and suburban areas (which include most of the building lots), especially in a humid and polluted atmosphere.

The oscillation of sol-air temperature penetrates the building component, and it eventually contributes to the heat flux entering the internal ambient temperature, which has an average density of $\overline{\mathrm{q}}_{\mathrm{i}}\left(\mathrm{W} \cdot \mathrm{m}^{-2}\right)$, an oscillation amplitude of the $\mathrm{n}^{\text {th }}$ harmonic $\left|\widehat{\mathrm{q}}_{\mathrm{i}, \mathrm{n}}\right|$ $\left(\mathrm{W} \cdot \mathrm{m}^{-2}\right)$, and a phase of $\varphi_{\mathrm{n}}(\mathrm{rad})$ :

$$
\mathrm{q}_{\mathrm{i}}(\mathrm{t})=\overline{\mathrm{q}}_{\mathrm{i}}+\sum_{\mathrm{n}=1}^{\infty}\left|\widehat{\mathrm{q}}_{\mathrm{i}, \mathrm{n}}\right| \cdot\left(\mathrm{n} \cdot 2 \pi \cdot \frac{\mathrm{t}}{\mathrm{t}_{0}}+\varphi_{\mathrm{n}}\right)
$$

The length of penetration of the harmonics decreases with their order $n$, therefore the analysis can be limited to the first order term $(n=1)$, which yields the most significant effects in the indoor space (see [24] for details). The deviation arising by the use of nonsinusoidal boundary conditions with respect to the sinusoidal one was found to be small and generally cautionary [30].

At the end, it can be verified that the average entering heat flux density is correlated through the U-value to the difference between the average sol-air temperature and the indoor temperature, the latter of which is assumed to be constant thanks to an ideal air conditioning system:

$$
\overline{\mathrm{q}}_{\mathrm{i}}=\mathrm{U} \cdot\left(\bar{\theta}_{\text {sol-air }}-\mathrm{T}_{\mathrm{i}}\right) \equiv \mathrm{U} \cdot\left(\overline{\mathrm{T}}_{\mathrm{e}}+\frac{1-\rho_{\mathrm{sol}}}{\mathrm{h}_{\mathrm{e}}} \cdot \overline{\mathrm{I}}_{\mathrm{sol}}-\mathrm{T}_{\mathrm{i}}\right) \cong \mathrm{U} \cdot\left(\overline{\mathrm{T}}_{\mathrm{e}}-\mathrm{T}_{\mathrm{i}}\right)+\mathrm{U} \cdot \frac{1-\rho_{\mathrm{sol}}}{\mathrm{h}_{\mathrm{e}}} \cdot \overline{\mathrm{I}}_{\mathrm{sol}}
$$

The first term of the final sum is controlled by the U-value alone and it may be comparatively low if $\bar{T}_{e} \cong T_{i}$, as it is often the case in urban areas, while the UHI effect shows up and is enhanced by a high humidity. Moreover, with constant indoor temperature and the analysis limited to the first order components, the oscillation amplitude of the entering heat flux density is correlated to the amplitude of the cycles of sol-air temperature and solar irradiance through the modulus of the (complex) periodic thermal transmittance $\mathrm{Y}_{\text {ie }}\left(\mathrm{W} \cdot \mathrm{m}^{-2} \cdot \mathrm{K}^{-1}\right)$ :

$$
\left|\widehat{\mathrm{q}}_{\mathrm{i}}\right| \leq \mathrm{Y}_{\mathrm{ie}} \cdot\left|\widehat{\theta}_{\text {sol-air }}\right| \cong \mathrm{Y}_{\mathrm{ie}} \cdot \frac{1-\rho_{\text {sol }}}{\mathrm{h}_{\mathrm{e}}} \cdot\left|\widehat{\mathrm{I}}_{\text {sol }}\right|
$$

$\mathrm{Y}_{\mathrm{ie}}$ is calculated according to [6] from the layer structure of the considered component and the thermophysical properties of the layer materials (thermal conductivity, density and specific heat). It is a representation of the heat flow cycle produced at the inner surface by a temperature oscillation at the outer side while the indoor temperature is maintained 
constant. The higher the thermal inertia is, the lower $Y_{i e}$ is, hence the upper limits have been set in Italy for $Y_{\text {ie }}[3]$ alongside those for $U$.

\subsection{The Solar Transmittance Factor (STF) and the Solar Transmittance Index (STI)}

A roof with high thermal mass but a dark surface may behave similar to a roof with a relatively low mass and thermal inertia but with a highly reflective surface. A highly reflective surface would almost nullify the effects of the solar cycle; nevertheless, it would be difficult to preserve due to soiling or biofouling, hence the lower solar reflectance of the aged surface must be considered [31,32]. Moreover, highly reflective surfaces are white, but different, less reflective colors may be compulsory for historical or traditional buildings or even entire urban areas. In these cases, thermal insulation and inertia increase their influence. A high thermal inertia, usually achieved by adopting a high mass, has an effective and substantially invariable thermal response, but it may conflict with seismic requirements, maximum allowed roof and wall thickness, costs, and even durability and fire risk if materials such as wooden fibers are used. In general, a proper set of performance parameters is not easy to select. Moreover, an arbitrary set of limiting values could be market distorting. Indeed, this work aims to respond to the need of easily selecting the most effective mix of surface and mass properties.

The daily average cooling power to be supplied by the AC system to offset the transmitted heat is correlated to the quantity calculated in Equation (10). Some supplementary power, however, may be required to ensure a constant operative temperature due to the daily variation of the sol-air temperature, which peaks at noon, affecting the ceiling radiant temperature. Approximating the solar irradiance cycle to a perfectly sine oscillation, in which the average value of the irradiance is made equal to its amplitude of oscillation, the peak cooling power to be provided by an AC system as calculated by Equations (10) and (11) is:

$\mathrm{q}_{\mathrm{i}, \text { peak }}=\overline{\mathrm{q}}_{\mathrm{i}}+\left|\widehat{\mathrm{q}}_{\mathrm{i}}\right| \leq \mathrm{U} \cdot \frac{1-\rho_{\text {sol }}}{\mathrm{h}_{\mathrm{e}}} \cdot \overline{\mathrm{I}}_{\text {sol }}+\mathrm{Y}_{\mathrm{ie}} \cdot \frac{1-\rho_{\text {sol }}}{\mathrm{h}_{\mathrm{e}}} \cdot\left|\widehat{\mathrm{I}}_{\text {sol }}\right| \cong\left(\mathrm{U}+\mathrm{Y}_{\mathrm{ie}}\right) \cdot \frac{1-\rho_{\text {sol }}}{\mathrm{h}_{\mathrm{e}}} \cdot \mathrm{I}_{\text {sol, max }}$

A comprehensive index has thus surfaced, which was called the 'solar transmittance factor' (STF) [24]. It includes both the radiative properties at the external surface and the thermophysical properties of the materials under the surface and is calculated as:

$$
\mathrm{STF}=\left(\mathrm{U}+\mathrm{Y}_{\mathrm{ie}}\right) \cdot \frac{1-\rho_{\text {sol }}}{\mathrm{h}_{\mathrm{e}}}
$$

A sketch of the thermal process expressed by Equation (12) is depicted in Figure 1, which shows how the cycle of the external surface temperature as induced by the solar cycle and controlled by the solar reflectance propagates through a building component. It in turn induces a cycle of the internal surface temperature, whose average and peak values are above the indoor temperature and thus yield an entering heat flux. The increase of the average internal surface temperature with respect to the inside air temperature is controlled by the steady-state thermal transmittance $U$, whereas the oscillation amplitude of the internal surface temperature is controlled by the modulus of the periodic thermal transmittance $Y_{\mathrm{ie}}$.

The solar transmittance factor (STF) is plotted in Figure 2 versus the whole spectrum of values of the solar reflectance $\rho_{\text {sol }}$. Since in Italy and other European countries a minimum insulation level is generally required for new or renovated buildings, two different $U$-values have been considered: $0.3 \mathrm{~W} \cdot \mathrm{m}^{-2} \cdot \mathrm{K}^{-1}$ (corresponding to a well-insulated roof or wall) and $0.8 \mathrm{~W} \cdot \mathrm{m}^{-2} \cdot \mathrm{K}^{-1}$ (a value often used to distinguish between insulated and non-insulated components). Moreover, $Y_{i e}$ is always lower than $U$, so values of the $Y_{i e} / U$ ratio have been considered from 1.00 (corresponding to a relatively massive component) down to 0.25 (corresponding to a lightweight component). The same environmental conditions prescribed for calculation of the solar reflectance index $[25,26]$ were used, considering 
a typical case of intermediate wind conditions and estimating temperature-dependent quantities such as $h_{e}$ by a recursive approach.

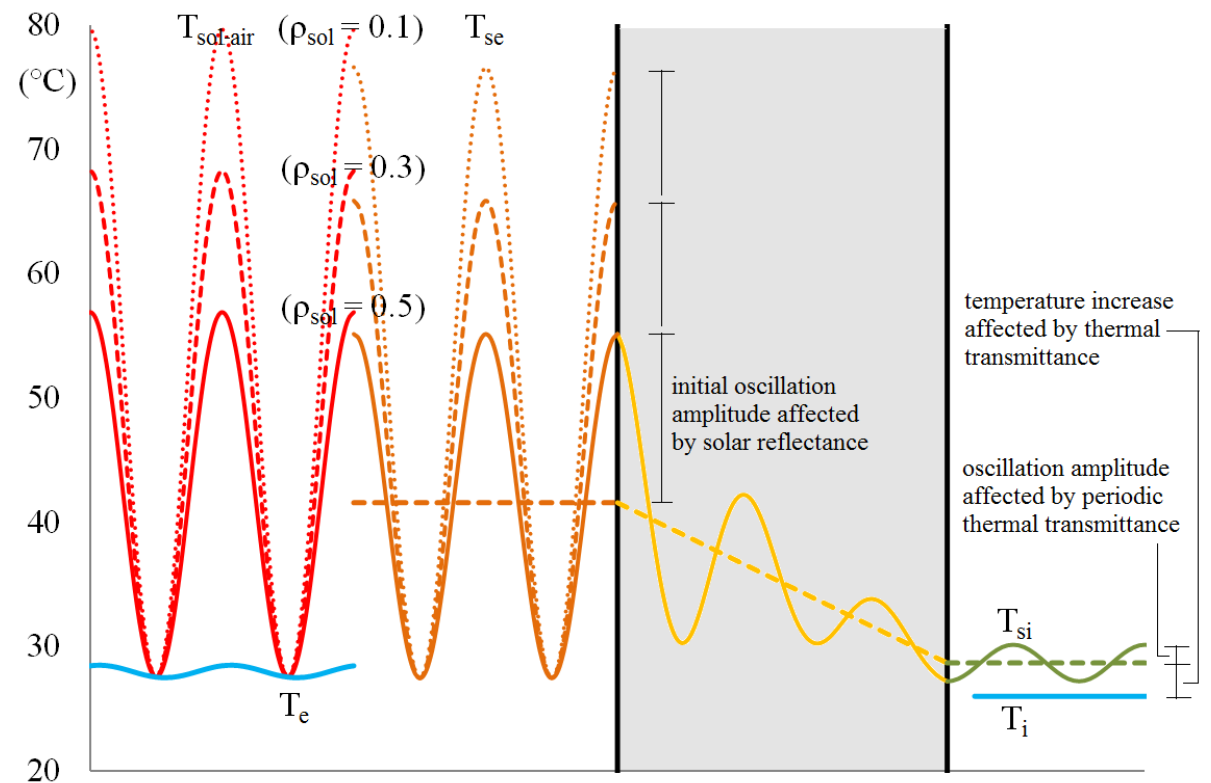

Figure 1. Cycle of the external surface temperature $\mathrm{T}_{\mathrm{se}}$ induced by the cycle of the sol-air temperature $\mathrm{T}_{\text {sol-air }}$ and controlled by the solar reflectance $\rho_{\text {sol }}$ : the cycle propagates through a building component and induces a cycle of the internal surface temperature $T_{s i}$ that has a peak value well above the internal ambient temperature $\mathrm{T}_{\mathrm{i}}$.

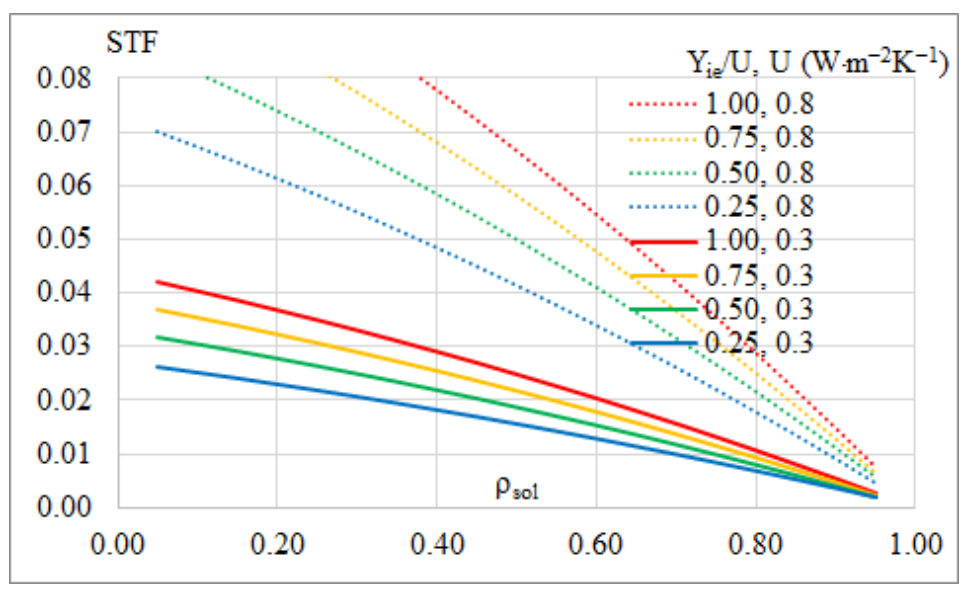

Figure 2. Solar transmittance factor (STF) versus solar reflectance $\rho_{\text {sol }}$ for intermediate wind conditions and $\mathrm{h}_{\mathrm{ce}}=12 \mathrm{~W} \cdot \mathrm{m}^{-2} \cdot \mathrm{K}^{-1}$, two different values of $\mathrm{U}$ (of an almost uninsulated component and a well-insulated component), and several values of $Y_{i e} / U$ (from a relatively massive component down to lightweight component with almost null mass).

It is interesting to observe in Figure 2 the comparatively lower weight of the $Y_{i e} / U$ ratio, i.e., of the thermal inertia, with respect to solar reflectance and thermal insulation. This agrees with the results reported in [18]. Above all, it is worthwhile to note that low values of the solar transmittance factor (e.g., STF $<0.01$ ) can be achieved with very different combinations of $\mathrm{U}, \mathrm{Y}_{\mathrm{ie}}$, and $\rho_{\mathrm{sol}}$.

The solar transmittance factor (STF) as defined by Equation (12) correlates the peak of the heat flux density that enters the inhabited space to the peak of the solar irradiance cycle, which is approximated to a sine cycle, under the additional approximation of similar 
internal and average external temperatures. From the peak of the entering heat flux density, one can estimate the peak of radiant temperature of the ceiling as follows:

$$
\mathrm{T}_{\text {si,peak }}-\mathrm{T}_{\mathrm{i}}=\frac{\mathrm{q}_{\mathrm{i}, \text { peak }}}{\mathrm{h}_{\mathrm{i}}} \approx \frac{\mathrm{STF}}{\mathrm{h}_{\mathrm{i}}} \cdot \frac{\mathrm{I}_{\text {sol,max }}}{2}
$$

The pre-calculated values of $h_{i}$, such as those suggested in [5] or [28], and analogous standards can be used, or a more precise value can be estimated by a recursive approach from Equation (3). The peak of the radiant ceiling temperature affects the operative temperature of the inhabited space (i.e., the weighted mean of air and mean radiant temperature), relevant to thermal comfort as it is the temperature perceived by the occupants. High values of such temperature can be a main source of thermal discomfort, also affecting cooling energy demand by requiring a lower temperature of the indoor air.

The STF would tend to yield very low values for high performance solutions, so it does not seem an effective choice for a performance indicator as it would not allow differentiating alternative building solutions. A similar issue was considered in [16] when the 'new' thermal performance index ${ }^{*}$ TPI was defined as the decrement of the peak of inner surface temperature with respect to a reference worst case, divided by the analogous decrement allowed by a reference optimal case, given in percentage terms. The same concept, clearly inspired by that for SRI calculation [25], can be applied in a more practical way, independent of the local weather conditions, by means of the solar transmittance index (STI) proposed in [24]:

$$
\mathrm{STI}=100 \cdot \frac{\mathrm{STF}_{\text {worst }}-\mathrm{STF}_{\text {tested }}}{\mathrm{STF}_{\text {worst }}-\mathrm{STF}_{\text {optimal }}}
$$

Since $\mathrm{T}_{\mathrm{i}}, \mathrm{h}_{\mathrm{i}}$, and $\mathrm{I}_{\text {sol,max }}$ are constant values in Equation (14), one can reason in terms of either inner surface temperature increase or entering heat flux density so the comparison of building solutions can be directly based on STF rather than $\mathrm{T}_{\text {si,peak }}$. In other words, STI represents the percent fraction of the peak heat flux density transmitted inside in the worst reference case that is cancelled by means of the considered building solution, evaluated in excess to the optimal reference case.

An issue still under investigation is the choice of the worst and optimal reference values of the solar transmittance factor (STF). A truly optimal case could be $\mathrm{STF}_{\text {optimal }}=0$. With this setting in Equation (15), values of STI in excess of $100 \%$ are avoided. A $100 \%$ performance, however, is practically impossible to approach and a different choice may thus be preferable, for example, that of a solution with a high insulation level, a high thermal inertia, and a high solar reflectance. In ref. [24], the choice of an externally insulated concrete slab (density $2400 \mathrm{~kg} \cdot \mathrm{m}^{-3}$ ) was proposed, with $20 \mathrm{~cm}$ thickness, $10 \mathrm{~cm}$ of added foam insulation (thermal conductivity $0.04 \mathrm{~W} \cdot \mathrm{m}^{-1} \cdot \mathrm{K}^{-1}$ ), and a solar reflective bright white surface $\left(\rho_{\text {sol }}=0.80\right)$, which achieves an STF value (i.e., $\left.\mathrm{STF}_{\text {optimal }}\right)$ as low as 0.007 . Regarding the reference worst case, a very low performing one such as an uninsulated metal slab with dark surface would cause an STI of high-performance building solutions always close to the best value of $100 \%$, obtaining a situation analogous to the direct use of STF. Therefore, a case with a relatively good performance would be preferable to increase differentiation. In [24], the choice of an externally insulated concrete slab was again proposed, with 5 or $10 \mathrm{~cm}$ of foam insulation but with the solar reflectance of a black surface $\left(\rho_{\mathrm{sol}}=0.05\right)$, which achieves an STF (i.e., STF $_{\text {worst }}$ ) equal to 0.051 or 0.028 , respectively. Values of STF and STI for a wide range of roof types and layer structures were also calculated and are summarized in Table 1.

One can observe that only solutions with a minimum insulation level and without dark coating show a positive STI. The combination of a non-null optimal case $\left(\mathrm{STF}_{\text {optimal }}=0.007\right)$ and the worst case with lower insulation $\left(5 \mathrm{~cm}, \mathrm{STF}_{\mathrm{worst}}=0.051\right)$ seems to provide higher positive values of STI, yet with a clear differentiation. Solar reflective (i.e., cool) solutions combined with heavy insulation provide high values of STI even if their thermal inertia is 
low. A solar reflective surface with low emissivity such as a bare metal has performance close to a dark surface. However, the problem of selecting proper reference cases is still open and will be addressed in future research based on statistical analysis of building lots.

Table 1. STI values for different roofing solutions and reference cases (low wind conditions).

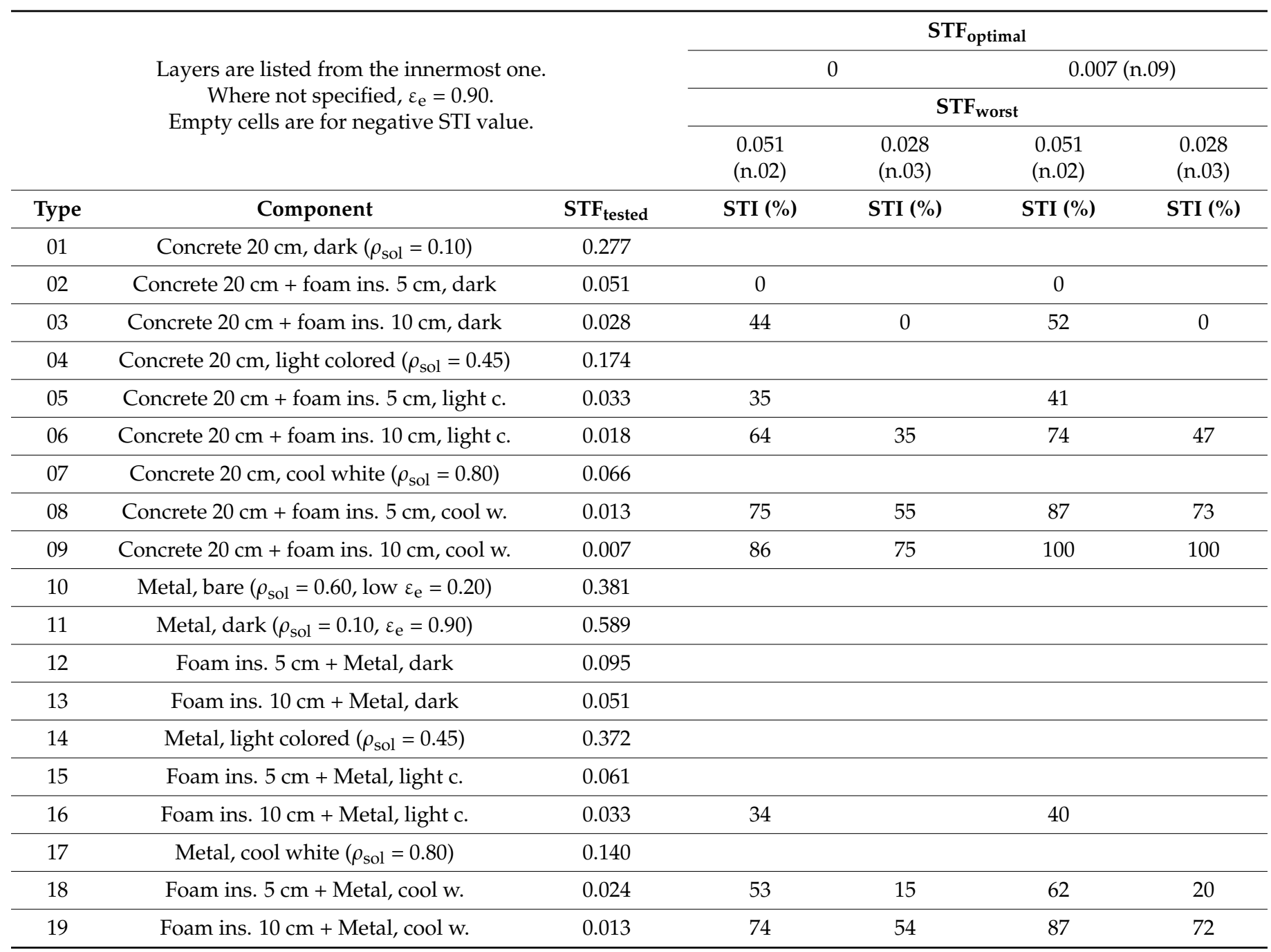

\section{Correlation of STF with the Component Performance}

In this work, the heat flux and the peak temperature were calculated by numerical simulation at the ceiling surface and were compared with the STF values for a relatively wide range of roof types and layer structures in different environmental conditions. TRNSYS 17 was used for the numerical simulation. A $3 \mathrm{~m}$ height single-zone building with a $3 \mathrm{~m} \times 3 \mathrm{~m}$ roof area was considered in the model, in which a constant inside air temperature of $26^{\circ} \mathrm{C}$ was fixed. All surfaces except the roof were set adiabatic, as the focus was on the thermal behavior of the roof alone. The considered locations were Milan (northern Italy, representative of a 'humid sub-tropical climate' (Cfa) according to the Köppen-Geiger climate classification [33]) and Palermo (southern Italy, representative of a 'hot-summer Mediterranean climate' (Csa).

The analysis extended from a light wooden roof, for which different types and levels of insulation were considered, to a concrete roof with different levels and positions of the insulation layer (see Table 2). Moreover, for each roofing solution, five different values were considered for the solar reflectance $\rho_{\text {sol }}=1-\alpha_{\text {sol }}$ : 0.1 (representative of a dark black surface), 0.3 (colored surface with relatively dark color), 0.5 (light colored surface), 
0.65 (aged white 'cool' surface), and 0.8 (bright white 'cool' surface). For all cases, highemissivity surfaces were considered, with a thermal emittance 0.9 .

Table 2. Roofing solutions considered in the numerical simulation.

\begin{tabular}{|c|c|c|c|c|c|}
\hline Roof Type & Roof Layers & $\begin{array}{l}\text { Conductivity } \\
\left(\mathrm{W} \cdot \mathrm{m}^{-1} \cdot \mathrm{K}^{-1}\right)\end{array}$ & $\begin{array}{c}\text { Density } \\
\left(\mathrm{kg} \cdot \mathrm{m}^{-3}\right)\end{array}$ & $\begin{array}{l}\text { Specific Heat } \\
\left(\mathrm{kJ} \cdot \mathrm{kg}^{-1} \cdot \mathrm{K}^{-1}\right)\end{array}$ & $\begin{array}{l}\text { Thickness } \\
\text { (mm) }\end{array}$ \\
\hline \multirow{6}{*}{$\begin{array}{l}\text { Light wooden } \\
\text { roof + rock wool (low } \\
\text { density) insulation } \\
\text { LWR + RW }\end{array}$} & Waterproofing membrane & 0.26 & 1300 & 1 & 1 \\
\hline & Wooden panel & 0.12 & 450 & 2.7 & 10 \\
\hline & Rock wool panel & 0.034 & 95 & 1.03 & $0 ; 40 ; 100 ; 180$ \\
\hline & Wooden panel & 0.12 & 450 & 2.7 & 10 \\
\hline & U-value $\left(\mathrm{W} \cdot \mathrm{m}^{-2} \cdot \mathrm{K}^{-1}\right)$ & \multicolumn{4}{|c|}{$2.980 ; 0.661 ; 0.305 ; 0.178$} \\
\hline & $\mathrm{Y}_{\text {ie }}\left(\mathrm{W} \cdot \mathrm{m}^{-2} \cdot \mathrm{K}^{-1}\right)$ & \multicolumn{4}{|c|}{$2.969 ; 0.655 ; 0.291 ; 0.135$} \\
\hline \multirow{6}{*}{$\begin{array}{l}\text { Light wooden } \\
\text { roof }+ \text { wood fiber } \\
\text { (low density) } \\
\text { insulation } \\
\text { LWR + WF }\end{array}$} & Waterproofing membrane & 0.26 & 1300 & 1 & 1 \\
\hline & Wooden panel & 0.12 & 450 & 2.7 & 10 \\
\hline & Wood fiber panel & 0.038 & 120 & 2.4 & $0 ; 40 ; 100 ; 180$ \\
\hline & Wooden panel & 0.12 & 450 & 2.7 & 10 \\
\hline & U-value $\left(\mathrm{W} \cdot \mathrm{m}^{-2} \cdot \mathrm{K}^{-1}\right)$ & \multicolumn{4}{|c|}{$2.980 ; 0.720 ; 0.337 ; 0.197$} \\
\hline & $\mathrm{Y}_{\mathrm{ie}}\left(\mathrm{W} \cdot \mathrm{m}^{-2} \cdot \mathrm{K}^{-1}\right)$ & \multicolumn{4}{|c|}{$2.969 ; 0.704 ; 0.265 ; 0.072$} \\
\hline \multirow{7}{*}{$\begin{array}{c}\text { Concrete } \\
\text { roof + polyurethane } \\
\text { foam insulation, } \\
\text { external } \\
\text { CR + PUe }\end{array}$} & Waterproofing membrane & 0.26 & 1300 & 1 & 1 \\
\hline & Polyurethane panel & 0.022 & 36 & 1.45 & $0 ; 50 ; 100$ \\
\hline & Reinforced concrete & 1.49 & 2200 & 0.88 & 50 \\
\hline & Concrete & 1.61 & 2200 & 1 & 60 \\
\hline & Plaster & 0.8 & 1600 & 1 & 1.5 \\
\hline & U-value $\left(\mathrm{W} \cdot \mathrm{m}^{-2} \cdot \mathrm{K}^{-1}\right)$ & \multicolumn{4}{|c|}{$4.318 ; 0.395 ; 0.208$} \\
\hline & $\mathrm{Y}_{\text {ie }}\left(\mathrm{W} \cdot \mathrm{m}^{-2} \cdot \mathrm{K}^{-1}\right)$ & \multicolumn{4}{|c|}{$2.855 ; 0.153 ; 0.077$} \\
\hline \multirow{7}{*}{$\begin{array}{c}\text { Concrete } \\
\text { roof + polyurethane } \\
\text { foam insulation, } \\
\text { internal } \\
\text { CR + PUi }\end{array}$} & Waterproofing membrane & 0.26 & 1300 & 1 & 1 \\
\hline & Reinforced concrete & 1.49 & 2200 & 0.88 & 50 \\
\hline & Concrete & 1.61 & 2200 & 1 & 60 \\
\hline & Polyurethane panel & 0.022 & 36 & 1.45 & $0 ; 50 ; 100$ \\
\hline & Plaster & 0.8 & 1600 & 1 & 1.5 \\
\hline & U-value $\left(\mathrm{W} \cdot \mathrm{m}^{-2} \cdot \mathrm{K}^{-1}\right)$ & \multicolumn{4}{|c|}{$4.318 ; 0.395 ; 0.208$} \\
\hline & $\mathrm{Y}_{\text {ie }}\left(\mathrm{W} \cdot \mathrm{m}^{-2} \cdot \mathrm{K}^{-1}\right)$ & \multicolumn{4}{|c|}{$2.855 ; 0.214 ; 0.108$} \\
\hline
\end{tabular}

The maximum increase of the ceiling temperature $\mathrm{T}_{\mathrm{si}}$ with respect to the indoor temperature $T_{i}$ is shown in Figure 3, as calculated for Milan and Palermo in the hottest month, for all considered roofing solutions. The total cooling energy demand along the summer season, from June to September, is also shown in Figure 4. A clear trend is evident in most cases, demonstrating a good correlation between the analyzed parameters and STF. Some scattering occurs for high performing solutions installed in Milan, where the outdoor temperature is often lower than the indoor temperature and reverse heat flows may take place during the day. On the other hand, a sharp correlation is evident throughout the whole range of the considered solutions for a hotter summer season such as that in Palermo, where STF seems the factor driving the thermal response of the roof component. 


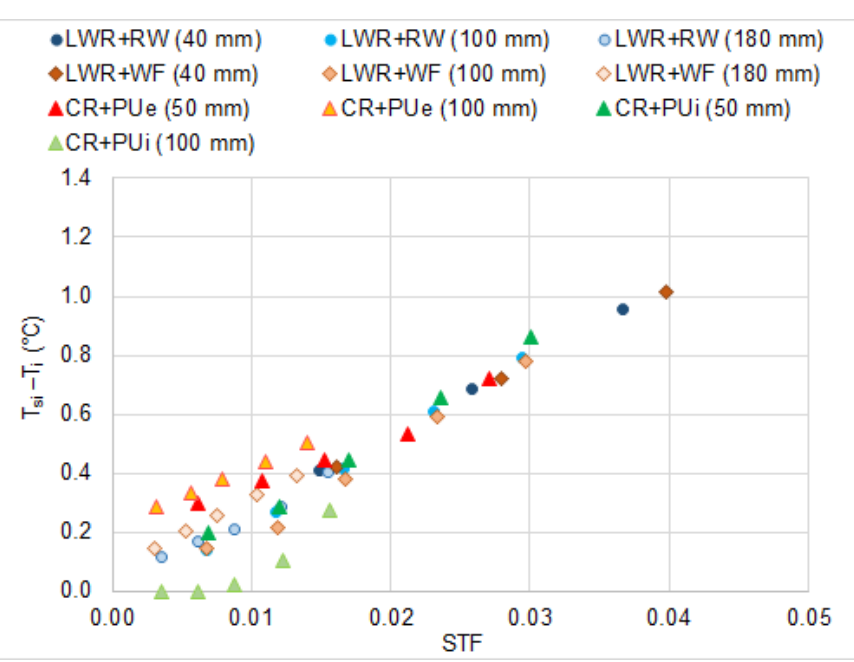

(a)

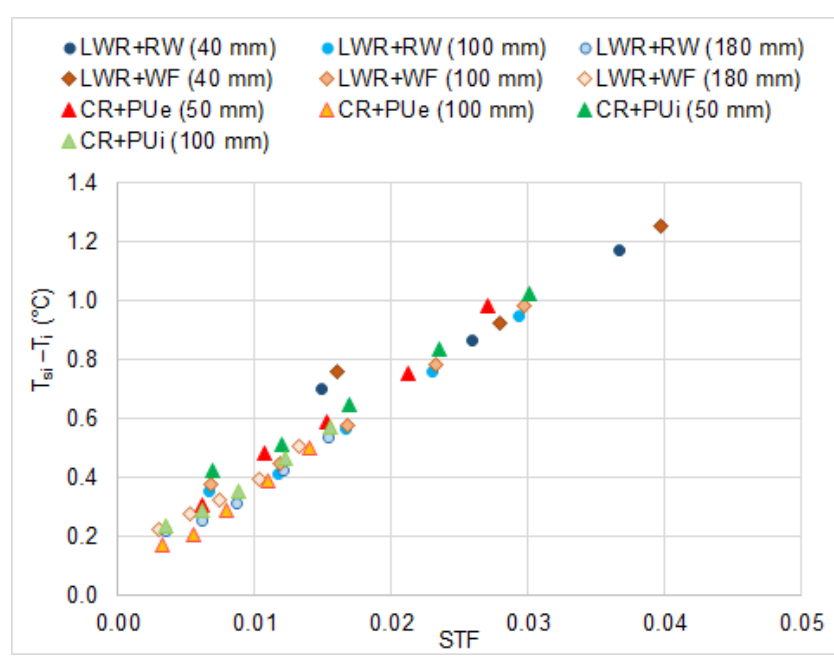

(b)

Figure 3. Increase of the ceiling temperature $T_{\mathrm{si}}$ with respect to the indoor temperature $\mathrm{T}_{\mathrm{i}}$. for different roofing solutions and insulation thickness. Five different values of STF are considered for each solution, calculated for five different values of the solar reflectance $\rho_{\text {sol }}$ (see Table 3): 0.8 (bright white 'cool' surface), 0.65 (aged white 'cool' surface), 0.5 (light colored surface), 0.3 (colored surface with relatively dark color), and 0.1 (dark black surface). (a) Milan, maximum temperature difference in July between ceiling and indoor temperature. (b) Palermo, maximum temperature difference in August between ceiling and indoor temperature.

Table 3. Solar transmittance factor (STF) for the considered roofing solutions and five different values of the solar reflectance (with $\mathrm{h}_{\mathrm{ce}}=12 \mathrm{~W} \cdot \mathrm{m}^{-2} \cdot \mathrm{K}^{-1}, \varepsilon_{\mathrm{e}}=0.9$ ).

\begin{tabular}{|c|c|c|c|c|c|c|c|}
\hline \multirow{3}{*}{ Roof Type and Insulation } & \multirow{3}{*}{$\underset{\left(W \cdot m^{-2} \cdot K^{-1}\right)}{U}$} & \multirow{3}{*}{$\begin{array}{c}\mathrm{Y}_{\mathrm{ie}} \\
\left(\mathrm{W} \cdot \mathrm{m}^{-2} \cdot \mathrm{K}^{-1}\right)\end{array}$} & \multicolumn{5}{|c|}{$\rho_{\text {sol }}$} \\
\hline & & & 0.80 & 0.65 & 0.50 & 0.30 & 0.10 \\
\hline & & & \multicolumn{5}{|c|}{ Solar Transmittance Factor (STF) } \\
\hline LWR & 2.980 & 2.969 & 0.067 & 0.117 & 0.166 & 0.230 & 0.294 \\
\hline $\mathrm{LWR}+\mathrm{RW} 040 \mathrm{~mm}$ & 0.661 & 0.655 & 0.015 & 0.026 & 0.037 & 0.051 & 0.065 \\
\hline LWR + RW $100 \mathrm{~mm}$ & 0.305 & 0.291 & 0.007 & 0.012 & 0.017 & 0.023 & 0.029 \\
\hline LWR + RW $180 \mathrm{~mm}$ & 0.178 & 0.135 & 0.004 & 0.006 & 0.009 & 0.012 & 0.015 \\
\hline $\mathrm{LWR}+\mathrm{WF} 040 \mathrm{~mm}$ & 0.720 & 0.704 & 0.016 & 0.028 & 0.040 & 0.055 & 0.070 \\
\hline LWR + WF $100 \mathrm{~mm}$ & 0.337 & 0.265 & 0.007 & 0.012 & 0.017 & 0.023 & 0.030 \\
\hline LWR + WF $180 \mathrm{~mm}$ & 0.197 & 0.072 & 0.003 & 0.005 & 0.008 & 0.010 & 0.013 \\
\hline CR & 3.896 & 2.855 & 0.076 & 0.133 & 0.188 & 0.261 & 0.333 \\
\hline $\mathrm{CR}+$ PUe $050 \mathrm{~mm}$ & 0.395 & 0.153 & 0.006 & 0.011 & 0.015 & 0.021 & 0.027 \\
\hline CR + PUe $100 \mathrm{~mm}$ & 0.208 & 0.077 & 0.003 & 0.006 & 0.008 & 0.011 & 0.014 \\
\hline CR + PUi $050 \mathrm{~mm}$ & 0.395 & 0.214 & 0.007 & 0.012 & 0.017 & 0.024 & 0.030 \\
\hline CR + PUi $100 \mathrm{~mm}$ & 0.208 & 0.108 & 0.004 & 0.006 & 0.009 & 0.012 & 0.016 \\
\hline
\end{tabular}




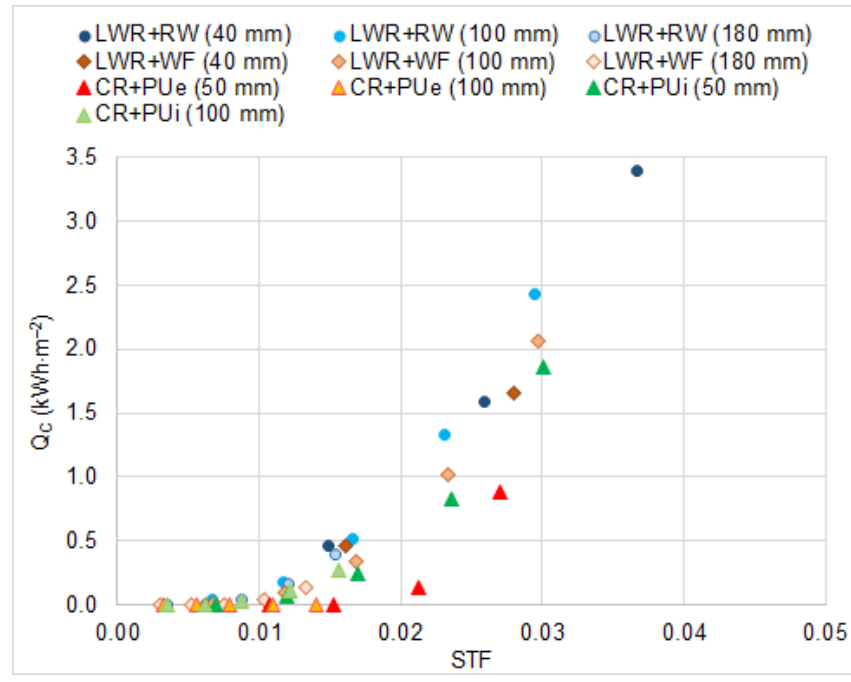

(a)

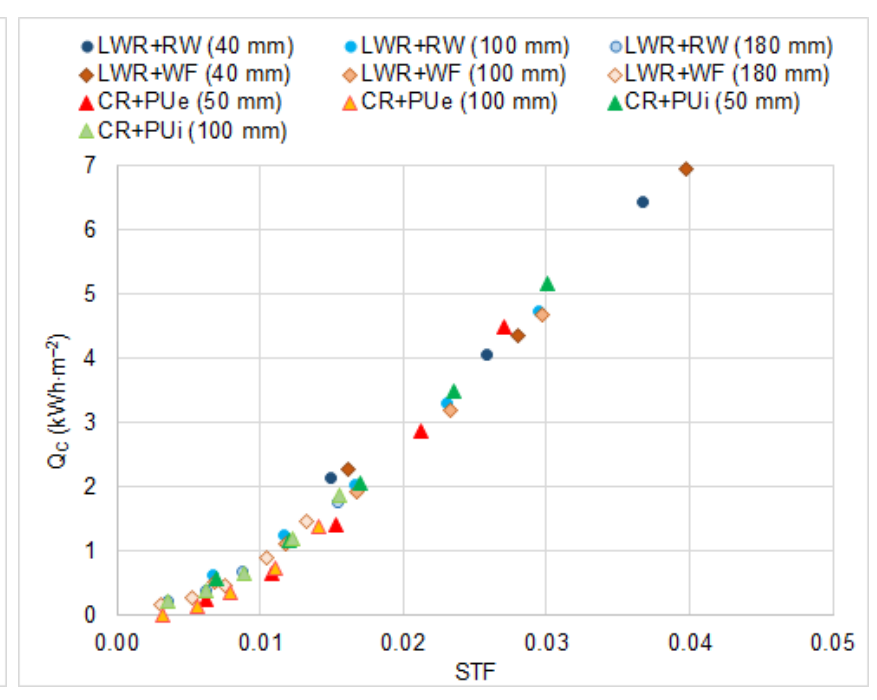

(b)

Figure 4. Total cooling energy demand in the summer season (June-September) for different roofing solutions and insulation thicknesses. Five different values of STF are considered for each solution, calculated for five different values of the solar reflectance $\rho_{\text {sol }}$ (see Table 3): 0.8 (bright white 'cool' surface), 0.65 (aged white 'cool' surface), 0.5 (light colored surface), 0.3 (colored surface with relatively dark color), and 0.1 (dark black surface). (a) Milan, seasonal cooling load. (b) Palermo, seasonal cooling load.

\section{Concluding Remarks}

A 'solar transmittance index' (STI) has been proposed for the energy rating of opaque building components. It is aimed to take into account, in a single performance parameter specifically targeted at the cooling season, the solar reflectance and thermal emittance of a component's external surface together with the thermophysical properties of the component materials relevant to thermal insulation and inertia. This may allow for a quick comparison of different solutions, thus helping the definition of component-based requirements and policies for building energy retrofit. The solutions can be easily implemented by designers and constructors or verified by regulatory institutions. The STI amplifies and enhances the significance of another purposely developed parameter on which it is built, the 'solar transmittance factor' (STF). This is calculated by a very simple formula from the U-value, the modulus of the periodic thermal transmittance, and the radiative properties of the considered component.

The relationship was investigated between STF and the ceiling temperature, which is relevant to the operative temperature indoors, as well as the relationship between STF and cooling energy demand over the cooling season, in Italian locations with different climates. The analysis extended from a light wooden roof, for which different types and levels of insulation were considered, to a concrete roof with different levels and positions of the insulation layer. A significant correlation was found over a relatively wide range of roof types and STF values, especially for a summer Mediterranean climate such as that in Palermo, southern Italy.

We plan to widen the range of considered roof types and extend the investigation to outer vertical walls. The analysis of new roof types would allow to further investigate the relationship among the relevant variables. Moreover, statistical analysis will be carried on existing roofs and their thermal characteristics, in order to identify proper reference values of STF to be used as worst case and optimal case in the calculation of STI.

Author Contributions: Conceptualization, A.M. and H.A.; methodology, A.M. and C.L.; software, C.L.; writing — original draft preparation, A.M., C.L. and P.T.; writing-review and editing H.A. and P.T. All authors have read and agreed to the published version of the manuscript.

Funding: This research received no external funding. 
Conflicts of Interest: The authors declare no conflict of interest.

\section{References}

1. International Organization for Standardization. ISO 13790:2008_Energy Performance of Buildings—Calculation of Energy Use for Space Heating and Cooling; Withdrawn; International Organization for Standardization: Geneva, Switzerland, 2008.

2. Libbra, A.; Muscio, A.; Siligardi, C. Energy performance of opaque building elements in summer: Analysis of a simplified calculation method in force in Italy. Energy Build. 2013, 64, 384-394. [CrossRef]

3. Italian Government. Inter-Ministerial Decree 26 June 2015 “Minimum Requirements”. Available online: www.mise.gov.it (accessed on 20 April 2021).

4. Italian Government. Ministerial Decree 6 August 2020 "Energy Efficiency". Available online: www.mise.gov.it (accessed on 20 April 2021).

5. ISO 6946:2017-Building Components and Building Elements_Thermal Resistance and Thermal Transmittance-Calculation Methods; International Organization for Standardization: Geneva, Switzerland, 2017.

6. EN ISO 13786:2017-Thermal Performance of Building Components_Dynamic Thermal Characteristics_Calculation Methods; International Organization for Standardization: Geneva, Switzerland, 2017.

7. ASTM C1549-16 Standard Test Method for Determination of Solar Reflectance Near Ambient Temperature Using a Portable Solar Reflectometer; ASTM International: West Conshohocken, PA, USA, 2016.

8. ASTM E903-20—Standard Test Method for Solar Absorptance, Reflectance, and Transmittance of Materials Using Integrating Spheres; ASTM International: West Conshohocken, PA, USA, 2020.

9. EN 15976:2011—Flexible Sheets for Waterproofing_Determination of Emissivity; European Committee for Standardization (CEN): Brussels, Belgium, 2011.

10. ASTM C1371-15 Standard Test Method for Determination of Emittance of Materials Near Room Temperature Using Portable Emissometers; ASTM International: West Conshohocken, PA, USA, 2015.

11. Zinzi, M.; Agnoli, S. Cool and green roofs: An energy and comfort comparison between passive cooling and mitigation urban heat island techniques for residential buildings in the Mediterranean region. Energy Build. 2012, 55, 66-76. [CrossRef]

12. Barrios, G.; Huelsz, G.; Rechtman, R.; Rojas, J. Wall/roof thermal performance differences between air-conditioned and non air-conditioned rooms. Energy Build. 2011, 43, 219-223. [CrossRef]

13. Barrios, G.; Huelsz, G.; Rojas, J.; Ochoa, J.M.; Marincic, I. Envelope wall/roof thermal performance parameters for non airconditioned buildings. Energy Build. 2012, 50, 120-127. [CrossRef]

14. Barrios, G.; Casa, J.M.; Huelsz, G.; Rojas, J. Ener-Habitat: An online numerical tool to evaluate the thermal performance of homogeneous and non-homogeneous envelope walls/roofs. Sol. Energy 2016, 131, 296-304. [CrossRef]

15. Cheng, V.; Ng, E.; Givoni, B. Effect of envelope colour and thermal mass on indoor temperatures in hot humid climate. Sol. Energy 2013, 78, 528-534. [CrossRef]

16. Chandra, P. Rating of Wall and Roof Sections-Thermal Considerations. Build. Environ. 1980, 15, 244-251. [CrossRef]

17. Kabre, C. A new thermal performance index for dwelling roofs in the warm humid tropics. Build. Environ. 2010, 45, 727-738. [CrossRef]

18. Zingre, K.T.; Kiran Kumar, D.E.V.S.; Wan, M.P. Analysing the effect of substrate properties on building envelope thermal performance in various climates. Energies 2020, 13, 5119. [CrossRef]

19. Thomas, L.P.; Marino, B.M.; Munoz, N. Steady-state and time-dependent heat fluxes through building envelope walls: A quantitative analysis to determine their relative significance all year round. J. Build. Eng. 2020, 29, 101122. [CrossRef]

20. Zingre, K.T.; Wan, M.P.; Wong, S.K.; Toh, W.B.T.; Lee, I.Y.L. Modelling of cool roof performance for double-skin roofs in tropical climate. Energy 2015, 82, 813-826. [CrossRef]

21. Omar, A.I.; David, D.; Vergnault, E.; Virgone, J.; Idriss, A.I. A new set of indicators to evaluate the bioclimatic performance of air conditioned buildings in a hot and humid climate. J. Build. Eng. 2020, 31, 101350. [CrossRef]

22. Kaboréa, M.; Bozonnet, E.; Salagnac, P.; Abadie, A. Indexes for passive building design in urban context—Indoor and outdoor cooling potentials. Energy Build. 2018, 173, 315-325. [CrossRef]

23. Pisello, A.L.; Goretti, M.; Cotana, F. A method for assessing buildings' energy efficiency by dynamic simulation and experimental activity. Appl. Energy 2012, 97, 419-429. [CrossRef]

24. Muscio, A.; Akbari, H. An index for the overall performance of opaque building elements subjected to solar radiation. Energy Build. 2017, 157, 184-194. [CrossRef]

25. ASTM E1980-11(2019)—Standard Practice for Calculating Solar Reflectance Index of Horizontal and Low-Sloped Opaque Surfaces; ASTM International: West Conshohocken, PA, USA, 2019.

26. Muscio, A. The solar reflectance index as a tool to forecast the heat released to the urban environment: Potentiality and assessment issues. Climate 2018, 6, 12. [CrossRef]

27. Torres-Quezada, J.; Coch, H.; Isalguè, A.; López, J. The roof impact on the heat balance of low height buildings at low latitudes, PLEA 2018-Smart and Healthy within the Two-Degree Limit. In Proceedings of the 34th International Conference on Passive and Low Energy Architecture (PLEA 2018), Hong Kong, China, 10-12 December 2018; Volume 3, pp. 937-938.

28. ASHRAE Handbook: Fundamentals; American Society of Heating, Refrigeration and Air-Conditioning Engineers: Atlanta, GA, USA, 2005. 
29. LEED ${ }^{\circledR}$ Green Building Program v4 for Building Design and Construction. U.S. Green Building Council. 2019. Available online: www.usgbc.org (accessed on 20 April 2021).

30. Gasparella, A.; Pernigotto, G.; Baratieri, M.; Baggio, P. Thermal dynamic transfer properties of the opaque envelope: Analytical and numerical tools for the assessment of the response to summer outdoor conditions. Energy Build. 2011, 43, 2509-2517. [CrossRef]

31. Paolini, R.; Terraneo, G.; Ferrari, C.; Sleiman, M.; Muscio, A.; Metrangolo, P.; Poli, T.; Destaillats, H.; Zinzi, M.; Levinson, R. Effects of soiling and weathering on the albedo of building envelope materials: Lessons learned from natural exposure in two European cities and tuning of a laboratory simulation practice. Sol. Energy Mater. Sol. Cells 2020, 205, 110264. [CrossRef]

32. Santunione, G.; Ferrari, C.; Siligardi, C.; Muscio, A.; Sgarbi, E. Accelerated biological ageing of solar reflective and aesthetically relevant building materials. Adv. Build. Energy Res. 2019, 13, 264-281. [CrossRef]

33. Beck, H.E.; Zimmermann, N.E.; McVicar, T.R.; Vergopolan, N.; Berg, A.; Wood, E.F. Present and future Köppen-Geiger climate classification maps at 1-km resolution. Sci. Data 2018, 5, 180214. [CrossRef] [PubMed] 